University of Nebraska - Lincoln

DigitalCommons@University of Nebraska - Lincoln

Fall 2009

\title{
Creating and Responding to the Gen(d)eralized Other: Women Miners' Community-Constructed Identities
}

\author{
Kristen Lucas \\ University of Nebraska-Lincoln, kristen.lucas@louisville.edu \\ Sarah J. Steimel \\ University of Nebraska-Lincoln
}

Follow this and additional works at: https://digitalcommons.unl.edu/commstudiespapers

Part of the Gender and Sexuality Commons, Gender, Race, Sexuality, and Ethnicity in Communication Commons, Organizational Communication Commons, and the Work, Economy and Organizations Commons

Lucas, Kristen and Steimel, Sarah J., "Creating and Responding to the Gen(d)eralized Other: Women Miners' Community-Constructed Identities" (2009). Papers in Communication Studies. 11.

https://digitalcommons.unl.edu/commstudiespapers/11

This Article is brought to you for free and open access by the Communication Studies, Department of at DigitalCommons@University of Nebraska - Lincoln. It has been accepted for inclusion in Papers in Communication Studies by an authorized administrator of DigitalCommons@University of Nebraska - Lincoln. 


\title{
Creating and Responding to the Gen(d)eralized Other: Women Miners' Community-Constructed Identities
}

\author{
Kristen Lucas and Sarah J. Steimel \\ University of Nebraska-Lincoln
}

An analysis of interviews with mining families reveals that gender identity construction is a collaborative process that draws upon broader community discourses. Male miners and non-mining women created a generalized other for women as "unfit to mine" (i.e., women are physically too weak to mine, are easy prey, and are ladies who do not belong in the mines). Female miners responded with gendered discourses that distanced themselves from and linked themselves to the generalized other. Keywords: blue-collar, gender, identity, symbolic interactionism, organizational communication

Communication research and theorizing consistently have documented the unique organizational and career challenges women face on the job: they must navigate complex gendered structural barriers (Buzzanell, 1995), they must discipline their "leaky" and aging bodies (Trethewey, 2000,2001 ), and they often face sexual harassment from supervisors, peers, and others (McGuire, Dougherty, \& Atkinson, 2006; Violanti, 1997), to name only a few. Additionally, women in blue-collar, workingclass occupations and organizations face another unique gendered challenge to successful organizational entry and day-to-day persistence. In masculine blue-collar organizational contexts, women workers' social identities as women (and in many cases, female/feminine) stand in sharp contrast to the very nature of their gendered occupations and organizations.

The purpose of this study is to gain insight into some of the complex experiences and identity negotiations of women in blue-collar work. In this article, we draw upon discourses from a mining community to get a glimpse of how women's identities are intersubjectively negotiated by the women working in mining and their community members. Drawing upon symbolic interactionism, we argue that the community at large-including the men who work in the mines and their female partners-create a highly gendered generalized other (which we term a "gen(d)eralized other") that positions women as unfit for mining. In response, the women who do work in the mines-particularly the daughters of male miners - reflect upon this

An earlier version of this paper was presented at the 2008 National Communication Association conference, San Diego, CA. 
composite looking glass self and respond by crafting identities that both distance themselves from and link themselves to the community-constructed gen(d)eralized other.

\section{Review of Literature}

In order to contextualize the current study, we begin by highlighting the gendered nature of blue-collar work. Second, we review current research on the negotiation of gendered identities in male-dominated occupations and organizations. Finally, we explain how symbolic interactionism can be used as a frame for understanding the role of community in individuals' identity development and negotiation.

\section{Gendered Nature of Blue-Collar Work}

The term "blue-collar" is a designation for skilled, semiskilled, and unskilled industrial work and/or workers. Typically, the core function of blue-collar jobs is centered on physical labor of some sort. According to the U.S. Census Bureau (2001), blue-collar occupations include (in decreasing order of average salary): precision production, craft, and repair; protective service (e.g., police); transportation and material moving; machine operators, assemblers, and inspectors; and handlers, equipment cleaners, helpers, and laborers.

The origin of the term blue-collar goes back to the traditional color of workshirts worn as protective clothing for certain categories of laborers. However, this color designation has a double meaning in that it also hearkens to the masculine gendered nature of the work itself. Buzzanell and Lucas (2006) explain that careers and their associated "collars" are inherently gendered. Specifically, blue-collar work typically is characterized as hyper-masculine, requiring a type of brute, physical masculinity, characterized by raw physical strength and a primal, savage sexuality (Fine, Weis, Addelston, Marusza, 1997). In contrast, pink-collar work is deemed feminine, emphasizing traits such as nurturing, relational maintenance, and emotional involvement (Ashcraft, 2006). White-collar work is associated with a "softer," refined masculinity that privileges rationality and competition, where workers rein in bodily excess to perform the higher work of the mind (Mumby, 1998). ${ }^{1}$

Not only is blue-collar work masculine, blue-collar occupations and organizations have been shown to be masculinized as well. For instance, Tracy and Scott (2006) articulate a form of masculinity for blue-collar 
firefighters and correctional officers that privileges sexual prowess, bravery, physical strength, and emotional restraint. In another example, Kitch (2007) explained that following the Sago, West Virginia, mine disaster in 2006 , the media presented a nostalgic gendered portrayal of miners as hard-working, rough and tumble family men. This media depiction is not too different from Wicks' (2002) analysis of institutional processes in one mining operation that drew upon gendered discourses of "real men" (e.g., tough, breadwinners) to desensitize miners to dirty, dangerous work. In police work, Prokos and Padavic (2002) described how the hidden curriculum taught police academy trainees rigid gender prescriptions that marked police work as masculine and women trainees as unwelcome.

Given the masculine culture of so many blue-collar organizations, there is scant space for the feminine. As such, it follows that women who enter blue-collar occupations and organizations likely face particularly difficult challenges to organizational entry and persistence. ${ }^{2}$ To make matters worse, Goffman (1963) explains that women in blue-collar jobs are stigmatized by both their coworkers and society: viewed by coworkers, they are not "man" enough to perform blue-collar work; viewed by society, their career choice marks them as not "feminine" enough. Therefore, women's constructions of their work-based gendered identities are particularly fraught with difficulty as they must strike a balance between masculine ideals of competence and sufficient femininity.

\section{Negotiating Gendered Identities in Masculine Organizations}

The gendered nature of blue-collar work itself creates unique gendered contexts and structures within which individuals' identities must be negotiated. Everyday organizational processes and practices produce social discourses of power that are appropriated, reproduced, and/or transformed in ways that both enable and constrain how members enact their professional identities (Trethewey, Scott, \& LeGreco, 2006). This is not intended to mean that individual identities are shaped entirely by work. Instead, individuals experience discourses at work that shape socially preferred identities. Further, attempts to develop a professional self often instill a gendered identity in individuals (Trethewey et al., 2006). Whereas bluecollar men have drawn upon the masculine nature of their respective organizations as a source of dignity, blue-collar women are faced with more complicated identity negotiations.

To explain, Ashforth and Kreiner (1999) outline several strategies that workers use to construct a positive identity given their otherwise stigma- 
tized "dirty work" status. One of these strategies is occupational ideological (re)framing. In some cases (Ashforth and Kreiner specifically cite construction work as an example), connecting to traditional notions of masculinity gives male workers a sense of meaning and positive social identity. Given that much blue-collar work can be considered dirty work, male blue-collar workers may find a sense of pride in traditionally masculine aspects of their jobs: physical strength requirements, dangerous working conditions, and even the dirtiness itself. In fact, Tracy and Scott (2006) explain that firefighters are viewed by society as heroes based, in part, on their job tasks that showcase masculine traits of courage and strength (e.g., saving lives, battling blazes). That is, the masculinity inherent in firefighters' jobs provides a status shield of prestige that compensates for the taint they may otherwise experience for having dirty jobs. In contrast, male correctional officers do not share the same prestige. Instead, they regularly struggle to combat the stigma associated with the feminized aspects of their work that contradict the masculine image they seek to uphold (e.g., serving food, collecting laundry). One of their reframing strategies is to present themselves in brutish, hypermasculinized ways to deflect the dirtiness and feminized taint of their jobs (e.g., demonstrating their toughness by labeling themselves "assholes").

Two other empirical studies of blue-collar organizations implicitly speak to men's occupationally bound identification with masculinity. Gibson and Papa's (2000) study of a manufacturing plant revealed that workers found a sense of pride in their hard work. By defining themselves as the "mud, blood, and beer guys [emphasis added]," they privileged the dirtiness, the danger, and the fraternal bonds of workers. Likewise, Lucas and Buzzanell (2004) demonstrated how a group of male miners used their highly masculinized work ethic as a yardstick for measuring the success (and, it could be argued, the "manliness") of their coworkers. In both instances, there was a sense of community built around the masculinity exhibited in the physical strength, endurance, and work ethic needed to succeed in the respective organizations.

Another way to demonstrate the masculinity-dignity connection is found in organizational members' responses to gendered identity threats, as was the case with pilots who clung to masculine images when their male-dominated profession was undergoing feminization (Ashcraft, 2005). In the face of aviation industry changes that call for collaborative crew-based decision-making, pilots lamented the decrease in (male) captains' power and authority. Further, they tied their identities to a strong, 
occupational identity embedded in gendered images of masculinity (i.e., rational, technical, paternal).

However, for blue-collar women workers, constructing a positive identity can be far more challenging in that their broader social identities as women are juxtaposed against their masculine work cultures. Research demonstrates that there are three primary ways in which women's occupational identities are constructed: reactively self-constructed, proactively self-constructed, and other-constructed. First, women in historically maledominated fields often reactively construct their identities in response to problematic workplace interactions. For instance, Yount (1991) identified three different identity constructions that women coal mine workers developed for dealing with their male coworkers who engaged in sexual harassment: ladies, who disengaged from the social context; flirts, who actively engaged in social relationships; and tomboys, who made efforts to be considered a member of the male work group. Similarly, Walk (1999) described different identity constructions adopted by women who worked as student trainers ("water girls") for men's intercollegiate sports teams (p. 271). According to Walk, women coped with their male coworkers' harassing and demeaning language by adopting three identities: moms, who engaged as caretakers for male athletes; sisters, who received "protection" from them; or ladies, women whose proper demeanor elicited respectful interaction from athletes.

Second, women proactively construct their own identities. Ashcraft and Pacanowsky (1996) argue that previous research on women in historically male-dominated fields viewed women as passive and reactive to masculine work environments. They, however, contend that women are active agents who communicatively construct the communities in which they work. Accordingly, communication research has begun to focus on the ways that women not only choose to react or adapt to historically maledominated fields, but also examines the way women are active agents in communicatively constructing their identity in those fields, particularly crafting their identities to fit within larger gendered occupational and/or organizational cultures. This is particularly the case when women enter into a traditionally male-dominated career field.

For example, in order to assimilate successfully, female workers from across a variety of blue-collar occupations have crafted masculine work identities that emphasize their ability to do the job by challenging their own associations with femininity, which further reinforced the culture of masculinity (Conn, 2004). In the oil industry, women adopted the gen- 
dered identities and reinforced the masculine value system privileged by their workplace (i.e., rugged individualism, idealization of the cowboy hero) (Miller, 2002). In commercial aviation, a critical examination of women's stories revealed that women had adapted to the airline culture (masculine/military values and practices) by changing their identity at work to "one of the lads" (Davey \& Davidson, 2000, p. 212).

Finally, men play a key role in constructing women's gendered identities. Prokos and Padavic (2002) explained that men play a key role in constructing gender hierarchies because they have the power/status in blue-collar work contexts. Men protected their gendered identities and status by degrading women through a variety of communicative tactics: treating women as outsiders, exaggerating gender differences, denigrating and objectifying women, and resisting women in authority. In this case, it was not what women did, but what men did to and around women that defined women's identities as second-rate police officers and unwelcome additions to the force. In a similar line of research, Paap (2006) studied the experiences of women working in construction. Paap outlined a "bitch, dyke, whore" taxonomy to explain how women's identities were constructed by the male workers. Women were classified-often without evidence-as bitches, women looking for a lawsuit; dykes, women who could do the work and therefore were deemed unfeminine and presumed to be gay; or whores, women who were perceived to be holding the job for the sole purpose of finding boyfriends.

\section{Symbolic Interactionism and the Role of Community in} Identity Negotiation

Identities are not produced in isolated contexts, but intersubjectively across contexts. Yet, one of the trends in the extant literature is to take an either-or approach to identity construction: examining women's construction of their own identities or men's construction of women's identities. Very few studies, if any, take a look at a more holistic approach to identity construction, particularly with regard to women's gendered identity in blue-collar work.

One approach to gaining a more robust understanding of gendered identity construction is through symbolic interactionism. Symbolic interactionism is a theory that states that people come to understand societal expectations, their sense of self, and their place in the world through interaction with others (Blumer, 1969, 1972; Mead, 1934). In other words, 
it is through intersubjective interaction with members of individuals' respective community/ies that they form their identity/ies. This process occurs when people view themselves through the lens of how other people perceive them (what Mead calls the "looking glass self"). Each person with whom someone interacts offers a single, unique looking glass self. The composite image created by all looking glass selves available to an individual is called the "generalized other" (Mead, 1934). In response to the generalized other, people come to understand themselves, develop their sense of identity, participate in their own socialization, and learn how to interact effectively with other members of society (Blumer, 1969, 1972; Glenn, 2007; Mead, 1934).

Following this theory, a complete understanding of identity must come from the negotiation between the individual and the generalized other. In other words, identity is constructed by multiple members of the community. Prokos and Padavic (2002) hinted toward a symbolic interactionism approach to identity construction when they stated that the outcome of gendered organizing and interactions among community members produced "gendered components of individual identity and a gendered frame for understanding other social structures" (p. 440). Further, wood and Frey (2007) recently noted that community has the ability to influence individuals' identity/ies through the influence attributes (e.g., ability to promote conformity, constructing a sense of us against them, creating patterns of appropriateness) and meaning-making attributes (e.g., establishing common beliefs, values, attitudes, expressing member and collective identities) inherent within communities.

Given the ability for community to influence behavior and engage in meaning-making for community members, it logically follows that community plays a pivotal role in establishing and maintaining identities for members. Therefore, the first step in understanding individuals' community-constructed identities is to learn about the meanings that community members assign to the "object"- to use a symbolic interactionism term-of women miners. Because objects' meanings arise through interaction, discourses of gender as they pertain to mining should reflect the meanings that community members hold for women miners. As such, we ask:

RQ 1: What are the community's predominant discourses of gender, particularly as related to women working in the mining industry? 
Taken together, these discourses should point to a general understanding of the gen(d)eralized other that is encountered by women who pursue employment in the mines. Put another way, these discourses are reflections of the multiple meanings that community members possess for women miners and, as such, combine to form the composite image that is the gen(d)eralized other reflected to women miners.

Because the gen(d)eralized other affects how individuals come to understand their own role and ultimately can influence how they behave in the community, we ask:

RQ 2: In response to this gen(d)eralized other, how do women from the community who work in the mines intersubjectively craft their own gender identities?

\section{Method}

\section{Context and Participants}

Mining culture, mining companies, and miners' masculinity went unchecked for generations, as U.S. employment laws forbade women from working in mining operations until 1973 (Sachs, 1997). Not surprisingly, when women finally did join the ranks - typically only following pressure from government agencies-there was considerable resistance from male employees who previously were insulated from sex-desegregation. As such, women's entrance into the industry was extremely slow. As recently as 2006, women still comprised only $13 \%$ of mine workers (and earned, on average, only $73 \%$ of men's wages, U.S. Census Bureau, 2006).

The community for this particular study is a small mining town in the upper Midwest, called "Irontown." 3 At Irontown Mining, Inc. (IMI), the integration of women into the workforce was slow as well. In 1974, the first year women worked in IMI mining operations, only 23 of the more than 2,900 workers were women $(<1 \%)$. By 2005 , women remained significantly underrepresented at approximately $4 \%$ of total employment.

In addition to regular employment, IMI also offers a "Summer Student Program." The program is a temporary employment option available to IMI workers' sons and daughters who were pursing college degrees. The "summer students," as they were called, worked at the mine during peak summer months for a competitive hourly wage. The money earned by a summer student typically was enough to pay for tuition for the following 
academic year. Additionally, IMI saved money by hiring students (e.g., paying wages but no benefits, avoiding hefty overtime pay for its senior employees) and helped to cover regular workers' requests for vacation time. Summer students worked at the same worksites as their fathers, performing the typical duties of regular mining production positions (e.g., 175-ton truck drivers, concentrator technicians, mechanical support).

The participants in this study were IMI employees and retirees $(n=21)$ and their wives $(n=16)$. All of the IMI employees and retirees were men, which was representative of the employment trends at IMI and in the mining industry at large. They ranged in age from their late 50 s through their late 70s. Additionally, a cohort of their adult sons $(n=13)$ and daughters $(n=12)$ were interviewed. The sons and daughters ranged in age from 32-41 (average age was 37); their educational attainment ranged from high school diplomas through graduate degrees. Their careers spanned a variety of industries: financial, medical, engineering, non-profit, education, military, sales and marketing, corrections, and construction/ skilled trades. ${ }^{4}$

A caveat is needed at the outset with regard to the participants. For the purpose of this study, "women who work in mining" are represented by a small subset of the overall sample: six daughters who worked at IMI in the Summer Student Program. ${ }^{5}$ As such, it must be emphasized that we are not claiming that these women's experiences and identity constructions are representative of all women miners. There are two primary reasons. First, despite women miners being a small population, the sample itself still is very small. Further, because these women worked as temporary labor, their experiences likely were different from what they would have been as permanent employees. That is, these women viewed their IMI jobs as means to achieving a college education and professional career, not as lifelong employment. That being said, however, these women can provide insight into opening conversations about women in mining. Not only have they worked in production positions, but they also come from mining families and, as such, are familiar with mining culture and practices. Therefore, as "insiders" within the broader mining community, they speak from a position informed by both their organizational/occupational and community memberships.

\section{Data Collection and Analysis}

Participants were recruited through a variety of methods in order to obtain the most diverse sample possible. Initial recruitment began with 
broad-based advertising, which included an e-mail announcement on an online alumni network in the community, flyers, and news stories and publicity in the local media. Additional recruitment was done via network and snowball sampling. In-depth, semi-structured interviews were conducted with participants at the site most comfortable and convenient for them, such as homes, restaurants, and workplaces. Fourteen of the miners and their spouses were interviewed as a couple, per their request. Additionally, eight phone interviews were conducted with people who lived out of the area (in-person and phone interviews revealed equally rich information).

The interview questions focused on occupational history and decision making, communication-based anticipatory socialization (e.g., stories, memorable messages), and on-the-job experiences that relate to those messages. Two lines of questions specifically addressed gender issues: (a) What kinds of work have the most dignity? Do you think there are differences for men and women? and (b) What do you think about the idea of "women's work" and "men's work"? In total, the interviews generated more than 60 hours of recorded talk.

Interviews were transcribed and verified against the original recordings. Because the goal was to have "near verbatim" transcripts, disfluencies (e.g., "um," "uh," stuttering) and side conversations (e.g., a server taking a lunch order) were not transcribed. Important gestures, laughter, and the like were noted in brackets. In total, transcription resulted in more than 1,000 pages of single-spaced text.

Guided by a grounded theory approach, data collection and analysis occurred simultaneously (Charmaz, 2000). Each interview was reviewed after it was complete, and the interviewer wrote a memo to capture dominant impressions and to make sense of the emerging patterns in the data (Miles \& Huberman, 1994).

Data analysis began by reading the transcribed interviews to gain a holistic understanding of both the miners' and the community members' perspectives on gender as it relates to mining work. Then, the data were selectively coded with qualitative data analysis software, identifying each textual unit that referenced women in mining, ranging from general attitudes to specific stories. In total, 52 textual units were coded, for 27 pages of single-spaced text. We used thematic analysis techniques (Lindlof, 1995; Owen, 1984) to categorize coded data and observations into broad semantic patterns. Specifically, Owen's (1984) criteria of recurrence (same meaning, different wording), repetition (same wording), and force- 
fulness (nonverbal cues that stress or subordinate words and phrases) were used to identify themes. Relationships among the themes were examined by both authors through a series of independent analyses and data sessions, interpreting the data in light of the research questions.

\section{Findings}

The first question guiding this analysis was: What are the community's predominant discourses of gender, particularly as related to women working in the mining industry? The majority of male miners reported that they had "no problem" with women working in the mines. Further, just as many wives stated that they firmly believed women deserve equal opportunities (e.g., "And my feelings are that if a woman can get a job with IMI and make that good hourly wage and get those good fringe benefits-especially if she's supporting a family - that she should be allowed to"). However, the men uniformly qualified their opinion with "just as long as they can do the job" and women deferred to their husbands' assessment of women's suitability for work in mining. ${ }^{6}$ Specifically, miners' and their wives' comments represented three primary discourses that centered on reasons why women could not perform the job as well as men and were unfit for mining: (a) women are physically too weak to mine, (b) women are easy prey in the mines, and (c) the mines are no place for ladies. Together these discourses represent the gen(d)eralized other of women miners.

\section{Discourses of the Gen(d)eralized Other}

Women Are Physically Too Weak To Mine. The first gendered discourse focused on women's physical stature and strength (more specifically their presumed lack thereof) as a detriment to their ability to be competent miners. Granted, the mining industry is one that can be physically grueling. Especially in past decades, much of the work required nothing short of brute strength (e.g., handling heavy equipment, drilling, lifting, hoisting, shoveling; see Lucas \& Buzzanell, 2004). Even with technological advances and equipment improvements that have eased many of the physical demands over the years, it still is a tough job and one that many community members believed could be successfully performed only by men. 
For example, after Bob asserted that sex should not play a factor in hiring, he explained that women's lack of strength, however, did cause problems in the mines:

And they have girls working there. And they'd be given jobs in the morning and if they had to hose the floor or something, they had to have someone go over and hook up the hoses 'cause they never had the strength to do it. I mean it wasn't their fault. But they just couldn't do it because of the heavy hoses and the big connectors and it takes a little strength to hook them up, you know. They didn't want the guys to going over to help them. But then the work wouldn't be getting done. So somebody would always stop to help them ... But what had happened, it made a lot of resentment within the working force.

In this case, women's lack of strength was viewed as a liability. Not only could they not perform their assigned tasks, but their need of physical help from men took men away from men's other duties. Bob questioned the rationale behind women being hired for specific jobs within the mine because "they were getting good pay for it and then somebody else [a man] would have to be over there helping them get the work started." Carl echoed the sentiment of women's physical weakness as a liability:

There are certain jobs that they [women] can do and certain jobs they can't. ... And they just couldn't do it. And pretty soon [Management] said, "Well, that's okay. Just do what you can do." But if it was a guy doing the job, he'd have to do it differently.

Here, women's lack of strength was perceived as lowering performance standards. That is, women would only be required to "do what they could do," which was presumably less than the standard performance required of male employees. Because of Carl's view of women as liabilities, he went as far as refusing the assistance of a female helper. He said, "I told the boss, I don't want one." He saw women's physical weakness as a greater liability than the benefits they could offer to him as a helper.

In the most extreme example, Larry (who reiterated several times that he had "no problem" with women working at the mines), viewed women and their physical weakness as the ultimate liability: 
Somebody might be depending on you physically, you know, especially as a miner. If I was working with a woman and she was physically not strong enough to ward something off, a problem. If something heavy was going to fall or something was going to happen and she couldn't push herself away or have enough strength to stop this-which most guys do-I'd be pretty scared to have her as a partner, you know. Because I might end up getting her hurt or she might end up getting me hurt or killed.

In this case, women's lack of physical strength is portrayed not only as an impediment to productivity, but as a danger to themselves, as well as to the men who work with them.

There were a few exceptions to the "women are physically too weak to mine" discourse, which were presented as just that, exceptions. But interestingly, when speaking about women who were tough enough to handle the job, participants discussed women in terms of their "manliness." Harold said, "I think that mining is definitely better for a man, but some of those gals are pretty tough." Vincent recalled one woman who worked on his crew saying, "She was as good as any man I've ever had. She could do anything." In the most blatant example of this discourse, Carl admitted that some women could perform mining work successfully: "And there's some women that are like men and they can do it." Finally, it is important to note that physical strength is not the only requirement for performing well on the job. Sam, a lifelong miner, explained, "Not every job out in the mines is all physical. So I mean, if you're driving a truck or if you're doing operating of certain things, you don't need a mass of muscles for that." Therefore, there were many mining tasks at which women could be equally if not more proficient than men. Yet when it came to talking about women's performance, strength was the only criterion that mattered.

Women Are Easy Prey in the Mines. The second gendered discourse was couched in concern for women's well-being in that they were portrayed as easy prey-especially sexual prey. As prey, women were described as in need of special protection, both physical and emotional, from the gritty and sexually explicit mining atmosphere. Because federal laws prohibited women from working in mines until the 1970s (Sachs, 1997), mines truly were a "boys club" that had embraced a hypermasculine culture. Occupational narratives and organizational artifacts from the mines before the integration of women into the workforce showed that 
sexual humor, crude language, and the treatment of women as sex objects were commonplace. For example, one snapshot shows an all-male work crew beaming at a Playboy centerfold during a lunch break. Also, stories from the first women to work in the mines confirm that they experienced ruthless sexual harassment on the job, especially during the first years of the integration.

The belief that women would be marked as easy prey was another way that community members presented women as unfit for mining. This particular discourse tended to emerge as a warning to incoming female workers. Kim, a woman who worked at IMI, recalls her father telling her to "Watch your back when you're working. You never know what someone's going to do to you." Her mother added, "We'd just tell her to stay away [from a particular person] and make sure that if you're near this person that there's somebody else around with you." Joanne and Jim gave their daughter, Jennifer, a similar warning. Jim began, "I remember talking to Jennifer about a couple of guys from IMI that ..." and Joanne interrupted, "that she should watch out for a little bit." Jim explained Joanne's caution by saying, "You know the miners ran the mine for many, many years and they just weren't accustomed to females being there."

These comments made to Kim and Jennifer signaled their parents' suspicion of potential sexual harassment. Kim was warned to not be alone with certain individuals. Similarly, Jennifer was told to "watch out" for men who "just weren't accustomed to females being there." These warnings were not simply advice on how to deal with general hazing, rough and tumble behavior, or "backstabbing" that could impede their careers. Instead, this advice displayed genuine concern for these women's safety on the jobsite. Put another way, they were put on alert to their status as prey and were urged to be situationally aware at all times and to take precautionary measures to protect their safety.

In another example, before Ed's daughter began her job as an IMI summer student, Ed warned her, "Don't let them harass you . . . . Just don't let them bug you. They're probably going to harass you, but don't let it." Ed explained that he believed that his daughter could become prey for harassment, "She's real tiny. And if I say so myself, she's really cute." From this statement, a woman-particularly one who fits the feminine physical appearance ideals of "tiny" and "cute"-is assumed to be a likely object of affection, desire, and harassment by male miners.

Notably, none of these parents recalled offering the same advice to their sons who worked at IMI. In fact, one parent explicitly voiced that women 
are uniquely in need of special protection. When asked about the advice he gave his daughter who worked in the mine, Dennis said he told her, "If anybody gives you any trouble-if you can't handle it-come see me and I'll take care of it for you. You know, I'll go see the guy." When asked if he gave the same offer to his son, Dennis laughed. "No," he said, "Danny can take care of himself. Danny is a big boy. He can take care of himself." In this instance, it is not only that Danny can take care of himself; it also is likely that he would not experience the same kind of "trouble" as his sister.

The "women are easy prey in the mines" discourse contributes to the image of women being unfit for mining by casting them as ready targets for undesired behavior. Being a target, to a certain extent, also marked the presence of women in the mines a liability. That is, women's presence somehow elicited the bad behavior (as in the case of Ed's daughter being tiny and cute), their presence calls the once hyper-sexualized organizational culture (which was embraced for generations) into question, and their need for special protection puts another burden on the men who are looking out for them.

The Mines Are No Place for Ladies. The third gendered discourse, while it focused on the mining culture itself, was based on a view of women as ladies. Like previous studies (e.g., Walk, 1999; Yount, 1991), this view of women ostensibly regards them as deserving of respect and respectful treatment on the basis of virtue and propriety. Yet, this view also serves to exclude women from full membership in the organization as the mines were depicted as "no place for ladies." That is, the environment was characterized as physically demanding, highly sexualized, crude, dirty, and dangerous. Whereas this kind of gritty worksite was an acceptable-if not desirable-place for men, it stood in stark contrast to an idealized workplace for ladies: not too physically taxing, decent, civilized, clean, and safe.

In fact, this particular discourse swayed some women from pursing employment in the mines. Brenda never even considered it an option, despite the fact that many of her friends did:

I knew friends that in the summers worked at the mine would make a large amount of money for college, to set away to go to college. And I think that opportunity might have been open, but my dad did not want us to pursue that. He didn't want me to pursue that for sure. It probably was okay for my brothers to 
pursue, but not for me. No, he just did not want me there in that environment.

Likewise, Mary's father repeatedly told her that he hoped women would never work in the mines because it is "no place for a woman." Victoria said that although her father never explicitly forbid her from working in the mines, "his tone always kind of inferred that it's really not a place for a woman."

Even though Victoria's father may not have directly told her about the environment, he did, in fact, believe it was no place for a lady. He remembered how he felt when "the ladies started coming to work at the mine":

I don't know that I wanted them there, because. Well, I guess I have to say no, I wouldn't have wanted them there. Because of the dirt and the abuse. I think they took a lot of abuse. There were a lot of men out there, you know, they were terrible the way they treated the women. So I guess, no, I wouldn't want them there.

Vincent was not the only one who spoke specifically of abuse. When asked his opinion about women working at the mines, Paul was adamant that women should stay out of the mines and compared the environment to North Country, a movie based on a class action sexual harassment lawsuit filed at a Minnesota iron ore mine in the 1980s. He said, "Well being that I grew up there, it was true to life of what was happening there .... The abuse that they [women] took. I don't think it was right." Ironically, his daughter worked as an IMI summer student.

When the presence of women could no longer be denied, some men made efforts to clean up the environment to make it a better place for women to work. For instance, Sam agreed that the mines were not an appropriate environment for women. He tried to improve the environment by keeping his interactions with women employees as professional as possible. Whereas he typically would exchange "B. S."-including crude or sexual humor-with his coworkers, he felt that the same behavior was inappropriate with a woman present:

At the beginning when they started hiring women at the mines, you know, that was a man's type of work .... So the best thing was be polite, but not just sit there and B.S. and all this kind of 
stuff, you know. Where maybe I would've done that with a guy, but not with a girl.

In another case, Carl was disappointed by the disrespectful treatment women experienced as they began entering mining and other "men's occupations." Specifically, he was offended by the language used in the mines in the presence of women, saying, "I think it downgrades a lady." Therefore, when he was a foreman, he forbid his crew from speaking coarsely in front of women. He explained, "In the mines it was, some of the language was bad. I didn't like the way they were talking with women present."

Despite efforts of men like Sam, who remained professional and respectful (albeit distant) in his interactions with women, and Carl, who insisted upon respectful treatment of women by all members of his work crew, the "mines are no place for ladies" discourse remained firmly entrenched. There were simply far more miners who, unlike Sam and Carl, were unwilling to change their ways or adapt the culture to which they had grown accustomed. This discourse naturalized the crudeness of the environment and served as a potential barrier to women wanting to pursue work at the mines. The lesson to be taken from this part of the discourse is that real ladies should not find the mines a desirable place to work.

In summary, these three interrelated discourses-women are physically too weak to mine, women are easy prey, and the mines are no place for ladies-collectively created a composite image that depicts women as unfit for mining. This community-constructed image, which was discursively created, represents a gen(d)eralized other with which women who worked in the mines interacted, came to understand the expectations others held of them, and developed their sense of self and their role in the world.

\section{Gendered Identity Strategies}

The second question guiding this analysis was: In response to this gen(d)eralized other, how do women from the community who work in the mines intersubjectively craft their own gender identities? The six women who worked at IMI revealed three different gender identity strategies they used to define themselves in relation to the gen(d)eralized other presented by their community: (a) I can be one of the guys, (b) I'm not like other women, and (c) I can be feminine, too. These strategies are neither sequential nor mutually exclusive. 
I Can Be One of the Guys. The first identity strategy used by the women in this study served as a rebuttal to the gen(d)eralized other created by their community. In particular, they responded to the discourses of their physical weakness by creating an identity that highlighted their physical strength and competence in mining activities. In this gender-distancing strategy, the women chose to identify themselves as one of the guys, as strong enough physically and mentally to work in the mines. Helen recounted a story told by her daughter: "She dug post holes with the guys to show them she could do it just as well as they could." This quotation not only reflects the theme that women are physically capable of being competent miners, but also shows that these women felt the need to offer direct rebuttals to the men in the mines who would have assumed them physically too weak to do the job.

In another example, Stephanie, whose tasks included shoveling rock onto conveyor belts, shoveling asbestos, and driving and maneuvering a 175-ton truck, described her work in terms of "strenuous," "hard," and "sweating," to name a few. She explained that male miners often were taken aback by her skill, "The talk amongst the workers was that there's this girl out there backing up better than these guys that have been there 30 years." By privileging the physical strength (and skill) required to complete those tasks and making note of the quality of her performance, Stephanie connected her identity to her ability to be one of the guys.

In addition to physical strength, some women proved that they could be one of the guys by participating in the sexually charged atmosphere at the mines. Oscar, an IMI employee who was responsible for caring for the locker rooms, understood that Playboy centerfolds were a mainstay of the men's locker room décor. However, he was outraged when he found a similar practice appear in the women's changing room (the women's facility did not have individual lockers). Oscar said, "I come in there one day and there was this big centerfold from Playgirl. In other words, a woman's magazine. Here's this big naked guy." Oscar promptly tore the picture down, crumpled it up, and threw it away (he said he never removed pictures from men's lockers). In this case, a woman presumably had decided to demonstrate that she too could distance herself from the feminine role of sexual prey by taking on a more aggressive role, one akin to how men treated women.

I'm Not Like Other Women. A second identity strategy used by these six women simultaneously rebutted and reinforced the gen(d)eralized 
other of women miners created by their community. In response to the positioning of women as unfit for mining, the women demonstrated their own personal suitability by essentially arguing "while other women are like that, I'm not like other women." Just as Conn (2004) found that women emphasized their competence by distancing themselves from accusations of femininity, some of these female mine workers used this gender-distancing strategy to describe themselves as different from other women at the mine. For example, Rachel contrasted herself with two other women at the worksite whom she described as whiney and soft. Rachel explained that she was the preferred summer student on her work crew:

At one point there were three girls working there. And, you know, I can remember one of the guys was saying, "Which one do you want [to help you with this job]? Do you want Rachel or Mandy?" "I'll take Rachel" And it was a lot of times because I was the one. You know, they'd tell me to do something and I'd do it. And sometimes, most of the time, the other two girls would sit there and they'd complain about their jobs. And, you know, there was one girl, if it was raining, she'd sit in the truck. And I'm like right out there working and stuff. And I guess, yeah, I had to prove myself working out there and stuff. But like I said, I got along well with the guys and I had no problem.

Rachel's statement combats the idea that all women are physically too weak or incapable of working in the mines, but ironically does so by reaffirming the feminine stereotype of women as whiners who typically would rather sit in the truck than do their jobs. Thus, Rachel breaks the stereotype as it applies to herself by reaffirming stereotypes about women in general.

Similarly, Jennifer alludes to how other women complained about sexual harassment and explicit language in the mines. She says, as a result:

When we started ... they used to get such huge lectures about sexual harassment and they weren't allowed to do anything when we were there. ... sometimes it would just slip out and they would swear. Then they'd say, "Oh, I'm sorry, I'm sorry." It was just so funny. I'm like, "I'm not going to sue you for sexual harassment because you swear." 
Though the men rushed to apologize assuming that she would be offended like the other women (or were afraid that she was, in Paap's (2006) terms, a "bitch" looking for a lawsuit), Jennifer established herself as different from other women by assuring the men that she would not sue them. Through various statements and actions, women distanced themselves from stereotypically feminine roles in order to develop an identity that resisted the gen(d)eralized other identity for themselves by confirming its salience for others.

I Can Be Feminine, Too. A third identity strategy adopted by the women interviewed was one that linked themselves to the positive attributes of their gender. That is, while they might be one of the guys or the exception among women, their feminine self also was present. In this way, the women could craft identities as both competent mine workers and feminine women. For example, Stephanie, one of the women who talked about being able to physically prove herself in the mines, explained that her competence was not the only part of her gendered performance important to her identity. The self-described "girly-girl" recalled:

It was very empowering to have a manly job. And still it was cute actually because some of the shovel operators would give me some candy before the shift would start. "Stephanie, come on here." And I would go and walk over there. And little Ralph would hand me a baggie of chocolate kisses and hard candies, "I've got little treats for you." So it's so funny thinking back. They still singled me out as a girl .... [The "girls"] were treated a little bit extra special by the guys with a little bit of candy:

In this statement, Stephanie indicates that her femininity - which included being "cute," "girly," and doted on by men-was important to her gendered identity at work. Not only did Stephanie's male coworkers recognize her for her competence ("backing up [her truck] better than these guys"), but they also could see past her "steel-toed work boots and safety glasses and hard hat" to appreciate her femininity. Thus, for Stephanie, this gender-linking strategy served the purpose of spotlighting the desirable aspects of her feminine gender.

However, this gender-affirming strategy was not without difficulty. In some instances, the "I can be feminine, too" strategy was highly problematic, as in the case of Kim. Like other women in this study, Kim described herself as competent at her job. However, she also talked about 
needing to adopt a feminine response to a man who constantly harassed her because she was a woman. For example, Kim described how she was chastised early in her employment for speaking her mind on political issues and learned quickly to watch what she said at all times. She explained, "I had a guy bring me-after a discussion of what women can and can't do-bring me a baggie of church literature on what my role was in God's eyes." Kim's lessons did not end there.

You know, I was always told to make a cheesecake. Supposedly, they had said my supervisor didn't like women, so you better bake him something so he'll be nice to you .... I did, one time, bring in cheesecake because they hounded me the entire time to bring in cheesecake.

She first attributed the gesture to an ongoing joke within the crew, but also wondered if there was something more than a joke.

Yeah, they were joking. But then you also wonder how much of it is, you know, you always had to take it in stride and not let them see that you were, you know, if it did bother you. They'd get you riled up because just that's what they wanted you to do.

I think I made one cheesecake and that was it.

As jokes were a central part of the masculinized workgroup culture at IMI, workers were expected to be able to "take a joke." But what made the cheesecake joke different from other pranks was the contentious gendered nature of it. Specifically, the intensity of the gendered messages in this particular workgroup context set up femininity as the antithesis of masculinity (i.e., competence, strength). In Kim's case, she crafted her response to the joke by drawing upon both masculine and feminine gender strategies. That is, she participated in the masculinized culture by playing along with the joke (which is consistent with the "I can be one of the guys" strategy), but did so by choosing to portray herself in a caricaturized version of femininity.

Although Kim was able to make a joke out of the situation, the underlying message - "be feminine"-was a serious mandate to which her response was required. On one hand, she resisted rigid, binary gender expectations by enacting both masculine and feminine identities. She showed her male coworkers that they could not get her "riled up" and she 
could "take it in stride" while simultaneously upholding traditionally feminine norms, which could be viewed as resistance against the positioning of masculine and feminine as oppositional terms. Further, her comment that she "made one cheesecake and that was it [emphasis added]" indicated that she drew the line on what they could expect from her, thereby resisting further attempts to make her fulfill a more traditional female token role (see Kanter, 1977). On the other hand, her move also reproduced the status quo. That is, Kim did not have much agency in choosing which gender performances to enact or how to enact them. She appeased the men in the workgroup by acquiescing to their "hounding." As such, this move reinforced men's power to set the gender rules for the organization. Further, because any resistance by Kim was not perceived by men as such, it ironically may have confirmed rather than resisted the gen(d)eralized other.

Taken together, the complex identity strategies enacted by these particular women revealed that they were aware of the gen(d)eralized other. Because competence was associated exclusively with masculine traits and values, women's gender-distancing identity strategies that linked them to masculinity ("I can be one of the guys") and separated themselves from stereotypes of women ("I'm not like other women") were necessary to establish their competence as miners. Yet, these strategies alone or in tandem were not enough. That is, they also had to uphold the positive aspect of the gen(d)eralized other, which was their highly regarded femininity. As such, they simultaneously engaged in a gender-linking identity strategy that highlighted their femininity, whether that was appreciating the special attention of a doting paternal figure in a friendly environment or knowing their place in a hostile one.

\section{Discussion}

The findings of this study show that that through community-based discourses, a gen(d)eralized other is created that assigns meaning to women miners. These meanings include the belief that women are not physically strong enough to mine, they are at risk of falling prey to sexual harassment, and they are unfit to handle the crude atmosphere of the mines. However, women's identity constructions do not stop there. In response to these meanings, a small cohort of women gained a sense of themselves and their place in the community by engaging gendered identity strategies that both distanced themselves from (i.e., expressing 
their masculinity, denying their femininity) and linked themselves to (i.e., spotlighting their femininity) the gen(d)eralized other.

While the focus of this analysis was on how these discourses constructed a gen(d)eralized other for women in a particular blue-collar community, every discourse also simultaneously defined men and reaffirmed their blue-collar masculinity: men are physically strong, they exude a fierce sexuality, and they can thrive in the rough and tumble environment of the mines. Furthermore, these discourses also positioned men as protectors of women's well-being (e.g., against sexual harassment) and gentlemen (e.g., able to be professional and respectful in their interactions with women).

The consequence of these discourses is not nearly as positive for women. The primary result of these discourses is that they created a complex and contradictory set of gendered identity rules that had to be negotiated by these women as they worked in the mines. That is, competence was linked exclusively to the masculine-attributed traits of physical strength and the ability to "take care of yourself." Therefore, in order to establish their credibility as miners, these women had to distance themselves from the femininity that was attached to them by virtue of the gen(d)eralized other (i.e., weak, in need of special protections). Yet, if they distanced themselves too far from their femininity, they risked harsh criticism of their male coworkers and other community members who, for the most part, still held traditional gender roles and expectations. Therefore, the women also had to link themselves to the gen(d)eralized other by spotlighting their femininity. Simply put, they were not afforded the benefit of being viewed as simultaneously competent and female and, instead, were required to (re)negotiate the balance of their gendered identity strategies on an ongoing basis.

More importantly, these gendered identity strategies do little, if anything, to challenge the gen(d)eralized other of women miners. Consistent with Ashcraft and Pacanowsky's (1996) finding that women may actively participate in historically male-dominated work cultures in ways that devalue other women and perpetuate gendered work identities, the identity strategies employed by these women appeared to reaffirm the status quo. Women miners who demonstrate their competence by being "tough like a guy" may perpetuate the notion that strength is the only relevant criteria for judging a worker's contributions. Additionally, women who base their claims of competence on being "not like other women" and present themselves as the exception rather than the rule may actually reinforce 
gender stereotypes of women as less competent than men. In neither of these strategies do women call for recognition of unique (perhaps feminine) skills that could be valuable within the organization (e.g., cooperation, problem-solving, communication). As a result, women and their performance continue to be measured with a masculine yardstick.

However, the gender-linking identity strategy of "I'm still feminine, too" appears to be an attempt to negotiate contradictory gender expectations by asserting that women can be both competent miners and ladylike. Though this study can argue for neither the success nor failure of that attempt, it does demonstrate that while identities are intersubjectively created in the interaction between the individual and community discourses, individuals do not simply accept the gen(d)eralized other presented to them at face value. Instead, individuals engage with that reflection to come to an understanding of themselves in light of the way social discourses structure gender in society.

Admittedly, the identity discourses revealed in this study are likely to vary for other communities, other blue-collar workers, and even for the community studied here. What is important, however, is that these discourses demonstrate that identities are not produced in isolation, but are (re)produced intersubjectively through negotiation between individuals and members of their community. While previous studies have largely focused on female blue-collar workers' identities as a function of either women's construction of their own identities or men's construction of women's identities, this study reveals that, consistent with symbolic interactionism, identity construction is a collaborative process that draws upon broader community and cultural discourses. In short, community plays a pivotal role in constructing its members' identities.

This study, while providing new insights into blue-collar women's identity constructions, does have limitations worth noting. First, the interview protocol was not designed explicitly to address the gendered nature of mining work. While a couple questions addressed gender issues in a broad sense (as described in the Method section above), no questions specifically asked IMI employees to discuss the role of women at the mines or summer students to recall gendered messages they had received. Therefore, the dataset is not nearly as robust as it could have been if there were more gender-based questions and follow-up probes. However, the fact that so many gendered messages emerged despite the interview protocol's nonspecificity on the issue reaffirms how vital this type of research is. As such, future research with a targeted interview protocol 
focusing on gendered in blue-collar organizations would be sure to reveal many additional, important insights.

Second, because of our small sample size, the findings from this study may have only limited transferability to the experience of women miners and/or women in blue-collar work. The women miners in this study were college students and temporary IMI workers. It is reasonable to expect that these women's experiences and, therefore, their identity constructions would be much different if they did not have the advantage of postsecondary education and the knowledge that their mining job was not a permanent or even long-term gig. Additionally, the presence of these women's fathers at their worksites (although not always on the same shift) surely had the effect of reducing the risks of being sexually harassed. Other women without family ties would not have the same benefit. Therefore, researchers should continue to explore how women across a variety of occupations (including blue-, white-, and pink-collar work) construct gendered identities and expectations in the presence of broader community discourses of work and gender-especially at organizations and in industries where women remain disproportionately underrepresented despite years of Equal Employment Opportunity legislation.

By continuing scholarship along these lines, researchers should be better able to understand how women in male-dominated fields negotiate their identities as both organizational members and as gendered beings. The more that can be learned about the challenges that women face in navigating their careers-from general gendered obstacles to unique occupation- and organization-specific barriers-the better women can be equipped to succeed in the future.

\section{References}

Ashcraft, K. L. (2005). Resistance through consent? Occupational identity, organizational form, and the maintenance of masculinity among commercial airline pilots. Management Communication Quarterly, 19, 67-90.

Ashcraft, K. L. (2006). Back to work: Sights/sites of difference in gender and organizational communication studies. In B. J. Dow \& J. T. Wood (Eds.), Sage handbook of gender and communication (pp. 97-122). Thousand Oaks, CA: Sage.

Ashcraft, K. L., \& Pacanowsky, M. E. (1996). "A woman's worst enemy": Reflections on a narrative of organizational life and female identity. Journal of Applied Communication Research, 24, 217-239.

Ashforth, B., \& Kreiner, G. E. (1999). "How can you do it?": Dirty work and the challenge of constructing positive identity. Academy of Management Review, 24, 413-434.

Blumer, H. (1969). Symbolic interactionism: Perspective and method. Englewood Cliffs, NJ: Prentice-Hall. 
Blumer, H. (1972). Symbolic interaction: An approach to human communication. In R. W. Budd \& B. Ruben (Eds.), Approaches to human communication (pp. 401-419). New York: Spartan Books.

Building a new job path for women. (2008, May 18). NBC news broadcast. Retrieved May 29, 2008, from http://www.msnbc.msn.com/id/21134540/vp/24696428\#24696428

Buzzanell, P. M. (1995). Reframing the glass ceiling as a socially constructed process: Implications for understanding and change. Communication Monographs, 62, 327 354.

Buzzanell, P. M., \& Lucas, K. (2006). Gendered stories of career: Unfolding discourses of time, space, and identity. In B. J. Dow \& J. T. Wood (Eds.), Sage handbook of gender and communication (pp. 161-178). Thousand Oaks, CA: Sage.

Charmaz, K. (2000). Grounded theory: Objectivist and constructivist methods. In N. K. Denzin \& Y. S. Lincoln (Eds.), Handbook of qualitative research (2nd ed., pp. 509-535). Thousand Oaks, CA: Sage.

Conn, C. E. (2004). Blue-collar women at work: A poststructuralist feminist reading of gendered identities and materiality. Unpublished dissertation, Purdue University, West Lafayette, IN.

Davey, C. L., \& Davidson, M. J. (2000). The right of passage? The experiences of female pilots in commercial aviation. Feminism \& Psychology, 10, 195-225.

Fine, M., Weis, L., Addelston, J., \& Marusza, J. (1997). (In)secure times: Constructing white working-class masculinities in the late 20th century. Gender \& Society, II, 52-68.

Gibson, M. K., \& Papa, M. J. (2000). The mud, the blood, and the beer guys: Organizational osmosis in blue-collar work groups. Journal of Applied Communication Research, 28, 68-88.

Glenn, C. (2007, May). Synthesizing symbolic interactionism and black feminism from the perspective of marginalized groups: Theoretical implications for negotiating identity and conflict through dialogue. Paper presented at the International Communication Association annual meeting, San Francisco, CA.

Goffman, E. (1963). Stigma: Notes on the management of spoiled identity. Englewood Cliffs, NJ: Prentice-Hall.

Kanter, R. M. (1977). Men and women of the corporation. New York: Basic Books.

Kitch, C. (2007). Mourning "men joined in peril and purpose": Working-class heroism in news repair of the Sago miners' story. Critical Studies in Media Communication, 24(2), 115-131.

Lindlof, T. R. (1995). Qualitative communication research methods. Thousand Oaks, CA: Sage.

Lucas, K., \& Buzzanell, P. M. (2004). Blue-collar work, career, and success: Occupational narratives of sisu. Journal of Applied Communication Research, 32, 273292.

McGuire, T., Dougherty, D. S., \& Atkinson, J. (2006). "Paradoxing the dialectic": The impact of patients' sexual harassment in the discursive construction of nurses' caregiving roles. Management Communication Quarterly, 19(3), 416-450.

Mead, G. H. (1934). Mind, self, and society. Chicago: University of Chicago.

Miles, M. B., \& Huberman, A. M. (1994). Qualitative data analysis: An expanded sourcebook (2nd ed.). Thousand Oaks, CA: Sage.

Miller, G. E. (2002). The frontier, entrepreneurialism, and engineers: Women coping with a web of masculinities in an organizational culture. Culture \& Organization, $8,145-160$.

Mishel, L., Bernstein, J., \& Allegretto, S. (2007). The state of working America 2006/2007. Ithaca, NY: ILR Press. 
Mumby, D. K. (1998). Organizing men: power, discourse, and the social construction of masculinity(s) in the workplace. Communication Theory, 8, 164-183.

Owen, W. F. (1984). Interpretive themes in relational communication. Quarterly Journal of Speech, 70, 274-287.

Paap, K. (2006). Working construction: Why white working-class men put themselves and the labor movement in harm's way. Ithaca, NY: ILR Press.

Padavic, I., \& Reskin, B. (2002). Women and men at work (2nd ed.). Thousand Oaks, CA: Pine Forge Press.

Prokos, A., \& Padavic, I. (2002). "There oughtta be a law against bitches": Masculinity lessons in police academy training. Gender, Work and Organization, 9, 439-459.

Sachs, C. E. (1997). Women working in the environment. London: Taylor and Francis.

Tracy, S. J., \& Scott, C. (2006). Sexuality, masculinity, and taint management among firefighters and correctional officers. Management Communication Quarterly, 20(1), 6-38.

Trethewey, A. (2000). Revisioning control: A feminist critique of disciplined bodies. In P. M. Buzzanell (Ed.), Rethinking organizational and managerial communication from feminist perspectives (pp. 107-127). Thousand Oaks, CA: Sage.

Trethewey, A. (2001). Reproducing and resisting the master narrative of decline: Midlife professional women's experiences of aging. Management Communication Quarterly, $15,183-226$.

Trethewey, A., Scott, C., \& LeGreco, M. (2006). Constructing embodied organizational identities: Commodifying, securing, and servicing professional bodies. In B. J. Dow \& J. T. Wood (Eds.), Sage handbook of gender and communication (pp. 123-141). Thousand Oaks, CA: Sage.

U.S. Census Bureau. (2001). Labor force, employment, and earnings.

U.S. Census Bureau. (2006). Industry by sex and median earnings in the past 12 months.

Underwood, E. D., \& Frey, L. R. (2007). Communication and community: Clarifying the connection across the communication community. In C. S. Beck (Ed.), Communication yearbook 31 (pp. 370-418). Thousand Oaks, CA: Sage.

Violanti, M. T. (1997). Men will be "boys" and women will be "whores": The case of the U.S. Navy's Tailhook scandal. In B. D. Sypher (Ed.), Case studies in organizational communication 2: Perspectives on contemporary work life (pp. 337-352). New York: Guilford Press.

Walk, S. R. (1999). Moms, sisters, and ladies: Women student trainers in men's intercollegiate sport. Men and Masculinities, 1(3), 268-283.

Wicks, D. (2002). Institutional bases of identity construction and reproduction: The case of underground coal mining. Gender, Work and Organization, 9, 308-335.

Yount, K. R. (1991). Ladies, flirts, and tomboys: Strategies for managing sexual harassment in an underground coal mine. Journal of Contemporary Ethnography, 19, 396-422.

\section{Notes}

'Color-based collar designations are neither discrete nor exhaustive categories. First, no uniformly applied rule exists for determining the collar color of various occupations. The U.S. Census Bureau (2001) and the Bureau of Labor Statistics (Mishel, Bernstein, \& Allegretto, 2007) use both a blue-collar/white-collar/service three-fold system and a blue-collar/white-collar dichotomous system for classifying all U.S. employees. The inconsistency arises when occupations that are considered service occupations in the former system are then classified as either blue- or white-collar in the latter. Second, the Census Bureau and BLS make mention only of blue- and white-collar 
categories and do not acknowledge other colors, such as pink or gray. As such, occupations that typically are considered, for example, pink-collar (e.g., secretaries) also are force fitted into the blue-white or blue-white-service divisions. Third, some occupations defy classification altogether (e.g., artists, medical lab technicians). Finally, it is important to note the terms blue-collar and working-class are not synonymous. While many blue-collar occupations are working-class, many working-class jobs are not blue-collar (e.g., food service, telemarketers).

${ }^{2}$ Unwelcoming gendered organizations have been cited as a possible reason for the underrepresentation of women in blue-collar occupations ("Building a new job path," 2008; Prokos \& Padavic, 2002). This is true especially because unionized, blue-collar jobs offer significantly better economic opportunities than other types of more traditional female-intensive work (e.g., retail sales, domestic work, child care), including higher wages, health care coverage, and job security ("Building a new job path," 2008; Mishel, Bernstein, \& Allegretto, 2007). Yet according to data from the most recent U.S. Census (2001), only $17 \%$ of blue-collar jobs are held by women. Moreover, the blue-collar jobs that provide the greatest amount of challenge and material reward (i.e., those in precision, production, and craft occupations), have the largest concentration of men, with women holding only $9 \%$ of such jobs. That means that among blue-collar workers, women are more than twice as likely to hold low-skilled blue-collar jobs as their male peers (see Mishel et al., 2007; Padavic \& Reskin, 2002).

${ }^{3}$ The names of the town, organization, and participants have been masked.

${ }^{4}$ Due to mass-scale deindustrialization in general and the volatility of the mining industry in particular, the mines were no longer a viable long-term employment option after 1980. Therefore, both sons and daughters were steered away from pursing mining as a career.

${ }^{5}$ Additionally, five of the sons worked in the Summer Student Program. These relatively low numbers for participation should not be taken as an indication of the undesirability of the Summer Student Program as not all members of the cohort sample were eligible for employment in the program. First, because the program was offered only during strong financial years, individuals whose college years coincided with financially troubled years missed the opportunity to participate. Second, because the program was only made available to individuals who were pursing college degrees, participants who did not pursue higher education also were excluded. Based on the years the program was offered and on individuals' college and military commitments, all participants (except one) who were eligible worked at IMI at least one summer.

${ }^{6}$ Throughout the interviews, husbands and wives were equally vocal. However, when it came to specifically addressing the role of women in the mines, women deferred to their husbands. As men expressed their opinions, women nodded in agreement, murmured "mmhmm" and "uh-huh" in support, and would sometimes echo the men's sentiments. For example, the wife of one miner who complained that women "can't do" certain jobs chimed in with a clarification, "because of strength." Another miner who asserted that men are better suited for mining than women had a wife who said, "I think there's a reason why we're one of each sex." But more importantly than what the women said, it was what women did not say. That is, no wives raised any challenges to their husbands' respective positions. Therefore, women's silence was an important discourse that reinforced the gen(d)eralized other. 